\title{
Red wood ants shape epiphytic lichen assemblages in montane silver fir forests
}

\author{
Luca Di Nuzzo ${ }^{(1)}$, \\ Alberto Masoni ${ }^{(1)}$, \\ Filippo Frizzi ${ }^{(1)}$, \\ Elisabetta Bianchi ${ }^{(1)}$, \\ Maria Beatrice Castellani ${ }^{(1)}$, \\ Paride Balzani ${ }^{(1-2)}$, \\ Federica Morandi ${ }^{(1)}$, \\ Ylenia Sozzi ${ }^{(1)}$, \\ Chiara Vallese ${ }^{(3)}$, \\ Giacomo Santini ${ }^{(1)}$, \\ Renato Benesperi ${ }^{(1)}$
}

\begin{abstract}
The Formica rufa group comprises several ant species which are collectively referred to as "red wood ants" (hereafter RWA). These species have key roles in forest ecosystems, where they are ecologically dominant and greatly influence the dynamics of the habitat they colonise. Various studies have shown how their trophic activity may affect other organisms, which include both other invertebrates and plants. We can therefore hypothesize that their presence could affect the taxonomic and functional composition of epiphytes, despite clear information on such an effect is lacking. This study aimed to fill this research gap by evaluating whether the presence of red wood ants could affect the structure and composition of lichen communities. We selected two sites on the Apennine Mountains in Italy, where the red wood ant F. paralugubris was introduced from the Alps more than $\mathbf{5 0}$ years ago. In each site, lichen assemblages on Abies alba trees located within the colonised areas were compared to those from nearby, non-occupied areas. The results allowed for the identification of significant effects of $F$. paralugubris on the structure of lichen communities. Although there was no detectable impact on lichen species richness, a significant difference in their community composition between colonised and control sites was detected. Furthermore, ant presence seemed to be associated with specific lichen functional traits such as asexual reproduction. We argue that RWA could affect the lichen community either directly, e.g., by actively dispersing the species capable of asexual reproduction through their movements on trees (ant-mediated dispersion), or indirectly through herbivore exclusion. Finally, we also observed differences in B-diversity among the colonised and non-colonised sites.
\end{abstract}

Keywords: Formica paralugubris, Red Wood Ants, Lichen Diversity, Impact, Introduced Species, Functional Diversity

\section{Introduction}

Animal-plant interactions are widespread and extend beyond the known consumerresource association in a wide array of relationships. As such, these interactions have long ago attracted the interest of scientists and today constitute an important field of research (Herrera \& Pellmyr 2009, Caradonna et al. 2021). Among the many documented examples, those involving arthropods, particularly ants species, are the most intriguing (Rico-Gray \& Oliveira 2007). Ants are one of the most diverse, abundant, and ecologically dominant animal groups worldwide, and their impact on ecosystem function is correspondingly significant (Lach et al. 2010). Most of the available literature is biased towards angiosperms, and comparatively little is known about other organisms such as lichens.

Lichens are symbiotic poikilohydric organisms formed by a fungus, the mycobiont, and one or more algae, the photobiont (Nash 2008). Together with bryophytes, these cryptogamic organisms represent an important component of forest ecosystems and biodiversity. They are key organisms in ecosystem functioning, since they are primary producers involved, for example, in water and nutrient cycles (Pike 1978,
Porada et al. 2018). Several interactions are known to occur between lichens and animals (Asplund \& Wardle 2017). Lichens can be a feeding substrate for both some vertebrates and several invertebrates. For example, gastropods are known to feed on lichens (Benesperi \& Tretiach 2004) and some species are specialised lichen-feeders (Kerney 1999). On the other hand, lichens provide a microhabitat where an organism could find particular temperature or moisture conditions. Invertebrates could find protection and food in the interface between the thallus and substrate, especially in the case of foliose lichens (André 1985). Moreover, although lichens rely mainly on wind for dispersion, several forms of zoochory by both invertebrates and vertebrates have been documented. In particular, ants can disperse both lichen soredia (Lorentsson \& Mattsson 1999) and thallus fragments (Heinken et al. 2007). Soredia can attach to ants' bodies during their passage on the surface of lichen thalli, or in some cases, wind-borne spores are carried in contact with ant body (Bailey 1970). In the case of thallus fragments, some ants use them to build nests, collecting fragments in the surrounding areas and thus providing maintenance of epigeous lichen 
Fig. 1 - Location of the study areas.

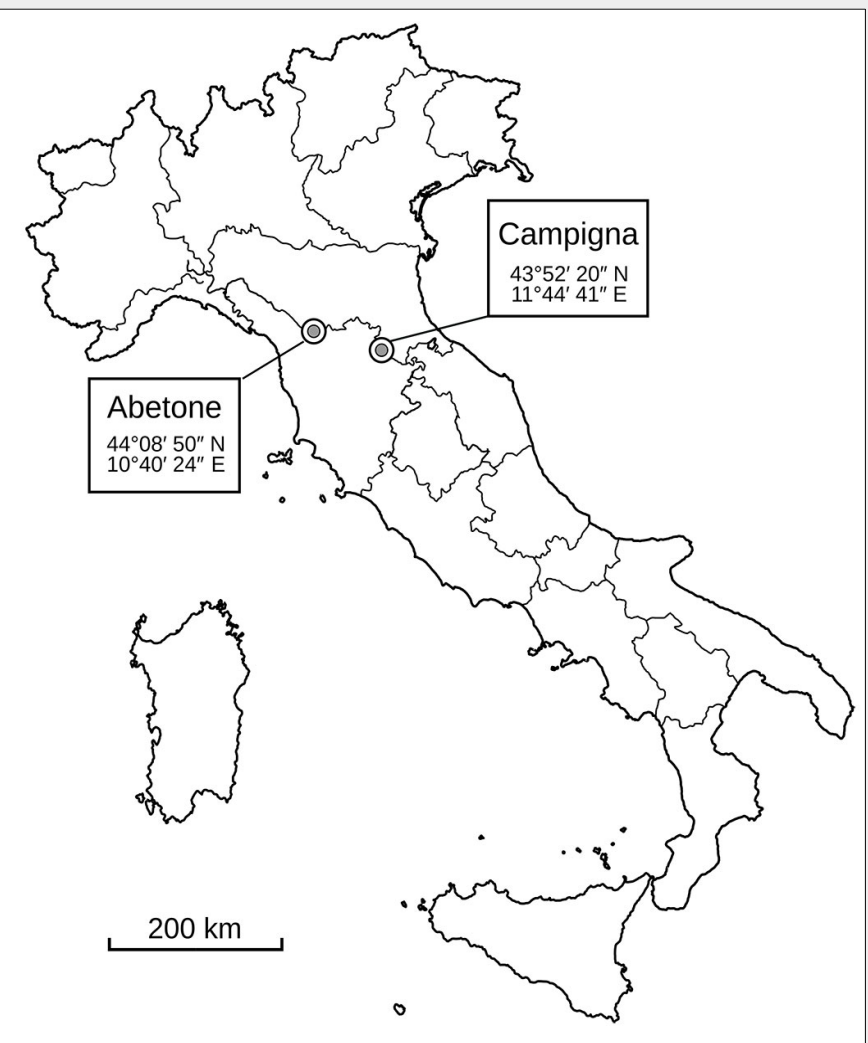

diversity (Heinken et al. 2007). This harvesting behaviour has also been investigated to explain the negative correlation between epiphytic macrolichen richness and ants (Thunes et al. 2018). Nevertheless, to the best of our knowledge, the effect of ants on the overall lichen epiphytic community has never been investigated.

Red wood ants (hereafter: RWA) are ecologically dominant species belonging to the Formica rufa group, with seven species described in Europe and at least 19 species reported in North America (Stockan \& Robinson 2016). RWA are cold-adapted species inhabiting coniferous woodlands (Risch \& Ellis 2016), and in the southern part of their range they are restricted to mountain areas, rarely occurring below $900 \mathrm{~m}$ a.s.l. In Italy, these species are widespread along the Alpine chain and only the more thermophilic Formica pratensis (Retzius, 1783) naturally occurs south of the Alps in the Apennine mountains. Moreover, starting in the mid-1900s, colonies of Formica lugubris (Zetterstedt, 1838), F. polyctena (Foerster, 1850) and F. aquilonia (Yarrow, 1955) were repeatedly transplanted as a biocontrol agent for forest insect pests from their original areas in the Alps to other sites in the Apennines, where they were formerly absent. The current status of most of the introduced populations is unknown. In a few cases, local extinctions have been documented, especially in less suitable and warmer areas, whereas some of the introduced populations have grown considerably (Frizzi et al. 2018, Balzani et al. 2021).

Most RWA have a strong influence on forest ecosystems (Wardle et al. 2011), affect-

\section{Materials and methods}

\section{Study areas and sampling}

The study was carried out in Abetone forest ( $\left.A B-44^{\circ} 08^{\prime} 50^{\prime \prime} \mathrm{N}, 10^{\circ} 40^{\prime} 24^{\prime \prime} \mathrm{E}\right)$ and in the Campigna Biogenetic Nature Reserve (hereafter referred to as Campigna, CA $43^{\circ} 52^{\prime} 20^{\prime \prime} \mathrm{N}, 11^{\circ} 44^{\prime} 41^{\prime \prime} \mathrm{E}$ ), where RWA populations have been transplanted since the late '50 (Groppali \& Crudele 2005 - Fig. 1). According to IV level Corine Land Cover for the Tuscany region, both sites can be classified as coniferous woodlands (CLC code 3123) dominated by white fir (Abies $a l b a)$. Both sites have similar elevational range (1200-1350 $\mathrm{m}$ a.s.l.) and the mean annual precipitation is $2325 \mathrm{~mm}$ and 1682.1 $\mathrm{mm}$ for Abetone (Bartolini et al. 2018) and Campigna (Gonnelli \& Bottacci 2009), respectively.

In Campigna, the RWA population is subdivided into several independent sub-populations displaced in the area, one of which is located in Avorniolo Alto, occupies an area of about 8 ha, and was chosen for this study (Frizzi et al. 2020). In the area of Abetone, a single population exists and covers an area of about 10 ha. Despite previous identifications described RWA populations in both areas as $F$. lugubris based on morphological characteristics (Groppali \& Crudele 2005), here the target populations were identified as F. paralugubris following the methods described in Masoni et al. (2019). The nest density per hectare was similar between sites (AB: $\sim 13$ nest ha ${ }^{-1}, C A$ : $\sim 12$ nests $\mathrm{ha}^{-1}$ ). For each area, we randomly selected three $F$. paralugubris nests spaced at least 150 metres from each other. Six silver fir (Abies alba Mill., 1759) trees located within $20 \mathrm{~m}$ from each nest were chosen to sample lichen communities. The fir trees were as evenly spaced in all directions around the nests as possible. Additionally, we randomly selected as control sites three points from nearby non-occupied areas, where F. paralugubris was known to be never introduced or present (Groppali \& Crudele 2005). As a result of their reproductive strategy based on colony budding, populations of this ant have sharp, easily recognisable boundaries (Chapuisat \& Keller 1999). Moreover, as these populations are under study since 2015, their boundaries are well mapped (Frizzi et al. 2018). The control areas shared similar environmental features of the occupied areas (i.e., altitude, type of forest stand, undergrowth, orientation, and slope). For each site, the lichen communities present on the randomly selected Abies trees were assessed.

Epiphytic lichens were sampled using four standard frames of $10 \times 50 \mathrm{~cm}$, subdivided into five $10 \times 10 \mathrm{~cm}$ quadrants as sampling grids, which were vertically attached to the tree trunk at three different heights above the soil (with the lower edge at 0, 50, and $100 \mathrm{~cm}$ ). At 0 and $100 \mathrm{~cm}$, the frames were attached at the cardinal points, while at 50 $\mathrm{cm}$, they were rotated by $45^{\circ}$ with respect 
to the cardinal points. All lichen species occurring within the frames were listed, and their frequency was recorded as the number of quadrats in which the species occurred. Most species were identified in the field, while critical specimens were collected and identified in the laboratory using standard stereo- and light microscopy techniques and chemical reagents. Following Nimis \& Martellos (2020), we described lichen diversity considering three functional traits evaluated for each species: growth form (GF), reproductive strategy (RS), and presence of lichenic acids (LA Tab. S1 in Supplementary material), which have been previously used to compare lichen communities (Giordani et al. 2016, Hurtado et al. 2020).

\section{Data analysis}

Differences in observed lichen species density (defined as the number of species observed in each sampled tree), carried out by comparing trees with and without RWA at both sites, were assessed using Generalised Linear Mixed Models (GLMM) with Poisson error distribution, including the nest as a random variable (Zuur et al. 2009).

Compositional differences within sites were investigated using multivariate techniques. The multivariate distances among samples were computed using the BrayCurtis dissimilarity index after fourth root transformation to reduce the influence of extreme values. We then performed nonMetric Multidimensional Scaling (nMDS) ordination analysis on the resulting distance matrix, according to Clarke \& Warwick (2001). As described in Anderson (2001), differences in species composition were tested within each site using a permutation-based non-parametric Multivariate Analysis of Variance (nPMANOVA), using the presence of the ants as the main fixed factor and the plot as a nested random factor.

For the analysis of functional traits, we computed the Community Weighted Mean (CWM), which represents the weighted mean trait in a community and accounts for the abundance of the species that carries the considered trait (Pla et al. 2012). The CWM of categorical traits was measured as the relative abundance of the category or group in the community, while the CWM of continuous traits was calculated as the trait average value (Lavorel et al. 2008). The computed CWM values were fitted onto the ordination axes using the function "envfit" of the Vegan/R package.

$\beta$-diversity was computed to evaluate the lichen species diversity and turnover among the areas tested. We applied the SDR simplex approach (Podani \& Schmera 2011), comparing for both areas the plots with and without F. paralugubris. We computed the three additive components of $\beta$ diversity: the relativized species replacement $(R)$, the relativized richness difference (D), and similarity (S). This method

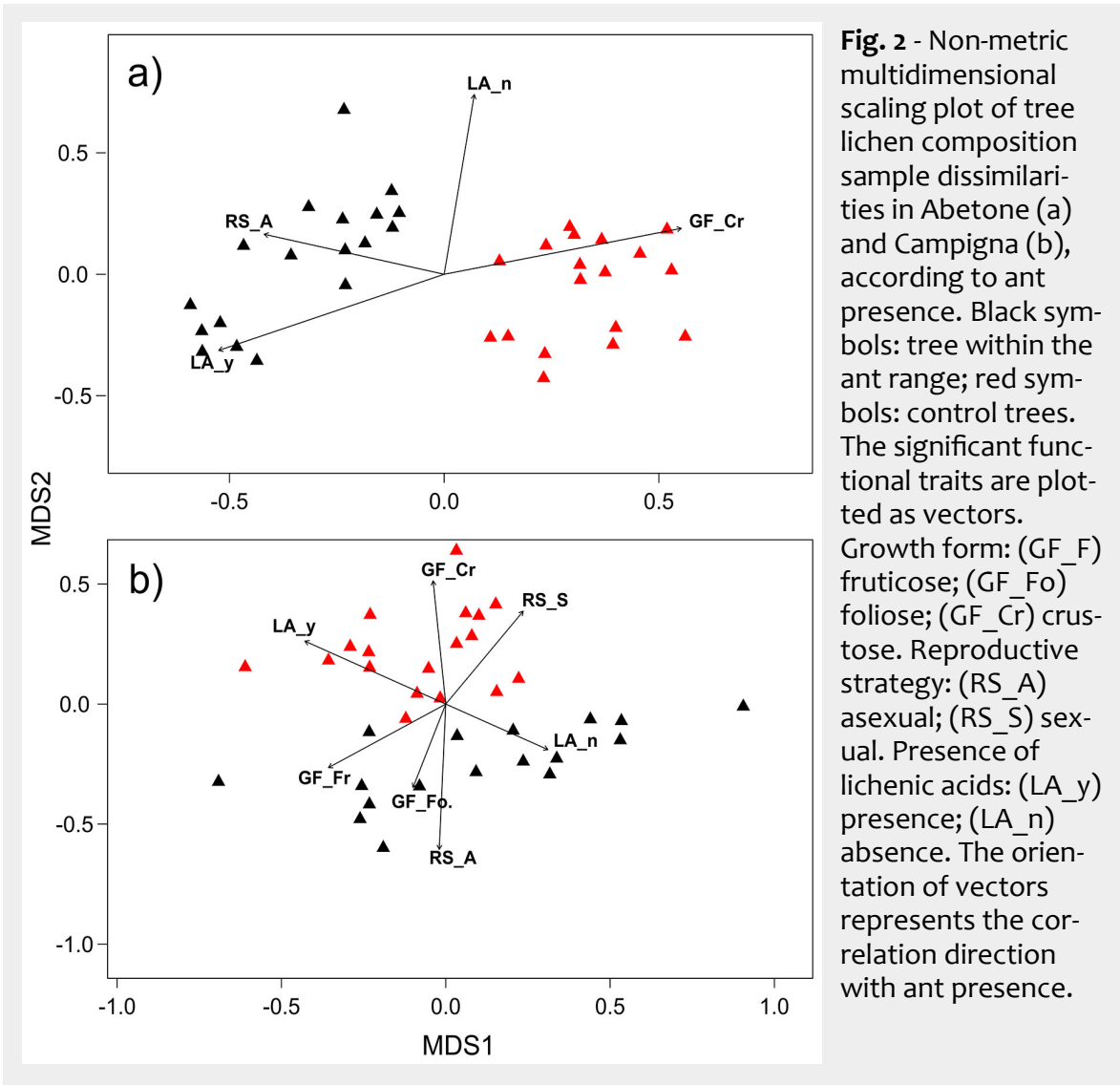

proceeded by comparing all pairs of plots and computing these three components of

65 lichen species (Tab. S1 in Supplementary material), belonging to 40 genera, whose density in both sites did not vary according to RWA presence $(z=-0.572, P=0.567)$. ence.

All analyses were carried out in R v. 3.6

Focusing on lichen species composition using the packages "vegan", "Ime4", within each site, nMDS ordination plots "FD", and "BiodiversityR".

\section{Results}

(Fig. 2) for both $A B$ (stress $=0.18$ ) and $C A$ (stress $=0.13$ ) showed a clear separation of ant-visited trees compared to those from On the 72 A. alba sampled trees we found control sites. In both $A B$ and $C A$ sites,

Tab. 1 - Correlation values between Community Weighted Mean (CWM) of each functional trait and ordination axes at both sites. For traits significantly correlated with axes, the type of effect summarizes whether RWA presence has a positive (+), negative (-) or no influence (n) on the trait. (o): not tested. Growth form: (GF_F) fruticose; (GF_Fo) foliose; (GF_Cr) crustose. Reproductive strategy: (RS_A) asexual; (RS_S) sexual. Presence of lichēenic acids: (LA_y) presence; (LA_n) absence.

\begin{tabular}{ccccc}
\hline Site & Trait & $\mathbf{r}^{2}$ & $\mathbf{P}$ & Direction \\
\hline \multirow{5}{*}{ Abetone } & GF_Cr & 0.3706 & 0.001 & - \\
\cline { 2 - 5 } & GF_Fo & 0.0422 & 0.514 & 0 \\
& GF_Fr & 0.0001 & 0.998 & 0 \\
\cline { 2 - 5 } & RS_A & 0.2208 & 0.021 & + \\
\cline { 2 - 5 } Campigna & RS_S & 0.0100 & 0.859 & 0 \\
& LA_n & 0.6009 & 0.001 & $\mathrm{n}$ \\
& LA_y & 0.4068 & 0.001 & + \\
& GF_Cr & 0.3658 & 0.002 & - \\
& GF_Fo & 0.1805 & 0.041 & + \\
& GF_Fr & 0.2723 & 0.004 & + \\
& RS_A & 0.5062 & 0.001 & + \\
& RS_S & 0.2833 & 0.006 & + \\
& LA_n & 0.1829 & 0.035 & - \\
\hline
\end{tabular}




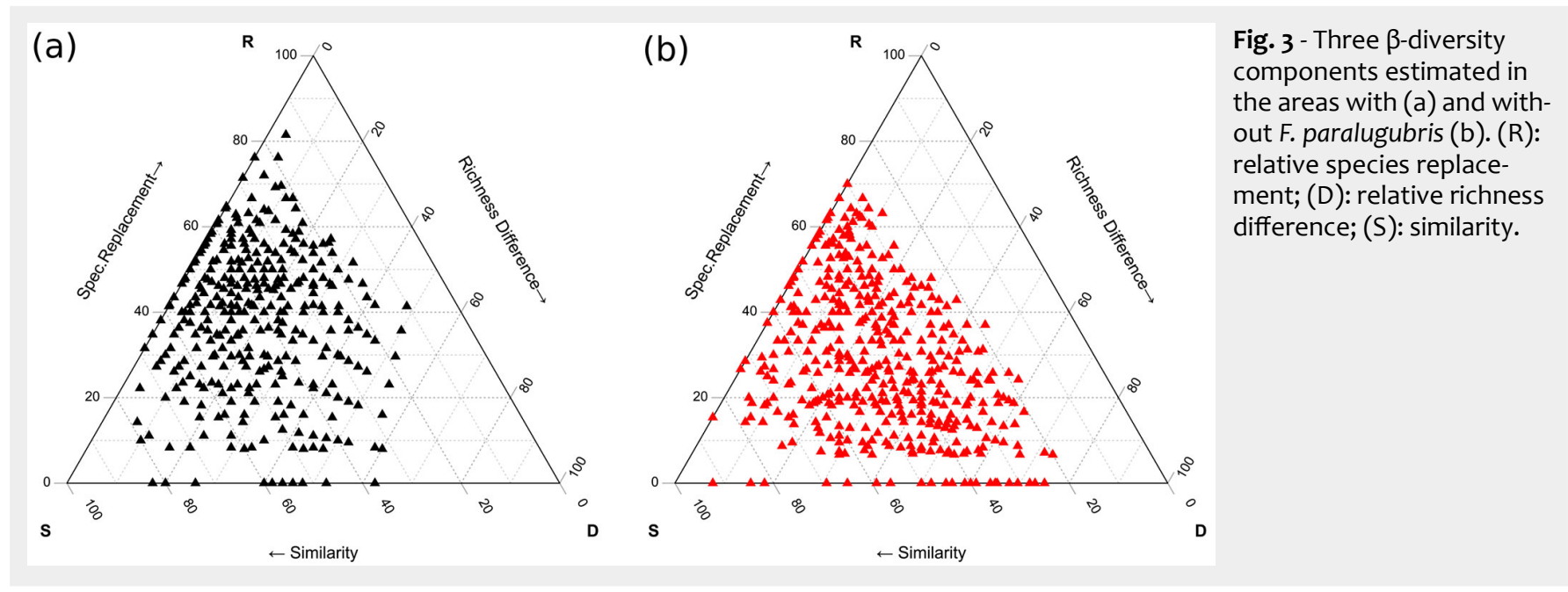

nPMANOVA revealed a significant effect of ant presence $\left(A B: F_{[1,2]}=27.77, P=0.001\right.$; CA: $F_{[1,2]}=11.15, P=0.001$ ), but also significant variability among plots within each site $\left(A B: F_{[1,4]}=5.50, P=0.001 ; C A: F_{[1,4]}=\right.$ $6.68, P=0.001)$.

CWM values varied according to ant presence (Tab. 1, Fig. 2). At Abetone, the crustose growth form (GF_Cr) was negatively associated with RWA presence, while the asexual reproductive strategy (RS A) and the presence of lichenic acids (LA_y) were positively associated with ants. This was also evident in the nMDS plot, where their vectors pointed toward the RWA-sites (Fig. 2a). In Campigna (Fig. 2b), the sites with ants were related with a higher abundance of lichen species with an absence of lichenic acids (LA_n), asexual reproductive strategy (RS A) and a foliose (GF Fo) and fruticose (GF_Fr) growth form. On the contrary, these sites were negatively related to crustose growth form (GF_Cr), presence of lichenic acids (LA y), and sexual reproductive strategy (RS_S). $\beta$-diversity results (Fig. 3) indicated that plots with RWA were more variable, with a higher value of species replacement $(R=37.4)$ and lower values of similarity $(S=41.5)$ and relative richness difference $(D=20.9)$ compared to control areas $(R=29.1, S=43.8, D=27.1)$.

\section{Discussion}

Overall, our results showed that the lichen epiphytic communities significantly varied according to RWA presence in the two surveyed areas. Ants affected lichen communities in terms of species composition. In particular, they seemed to affect lichen functional traits, favouring species with asexual reproduction. One possible explanation is that they unintentionally transport lichen propagules during their movements, acting as a vector for lichen asexual dispersion in surrounding trees (Lorentsson \& Mattsson 1999).

In our sites, lichen richness was not affected by ant presence. Lichen epiphytic diversity, in terms of species number, has been shown to be influenced more by macroclimatic factors than specific habitat fea- tures (Matteucci et al. 2012). Thus, the overall epiphytic lichen diversity may not be a good proxy for assessing possible effects on lichen diversity carried out by ants. Our results differed from previous studies that found a negative influence of ant presence on lichen species richness (Lorentsson \& Mattsson 1999, Thunes et al. 2018). However, these studies focused on both lichens growing on trees and on other substrates. Thus, ant effects may differ depending on which lichen community is considered (epiphytic vs. terricolous). Thalli fragments of terricolous lichen species were usually found in ant mounds, supporting this hypothesis (Heinken et al. 2007). Moreover, Thunes et al. (2018) considered $F$. aquilonia, which could have a distinct behavioural patterns compared to $F$. paralugubris, thus influencing cryptogam communities differently. F. paralugubris has been introduced in the studied forests, so we could not exclude different behavioural patterns compared to the original ants' populations in the Alps or in other autochthonous areas of Europe.

The major influence of ants on lichen epiphytic communities seemed to be mediated by functional traits. Plots with ants displayed a greater presence of lichens with asexual reproduction as soredia and isidia and fewer crustose species. Previous research has reported that soredia could attach to ants when the latter pass over lichen thalli (Lorentsson \& Mattsson 1999). Thus, our finding corroborates the hypothesis that ants could act as a dispersion vector of lichen soredia, transporting them onto other trees and enhancing their colonisation. To date, evidence of ant interaction with isidia is lacking, but we argue that continuous movements over lichen thalli could enhance the detachment of these propagules, favouring their dispersion. Wood ants establish complex networks of foraging routes that radiate to nearby trees and connect different nests (Ellis \& Robinson 2016). These trail networks change dynamically to track temporal changes in resource availability, mainly aphid colonies, and allow an efficient and almost uniform exploitation of the area surrounding the colony (Buhl et al. 2009). As a consequence, isidia and soredia could travel through this network, potentially dispersing to other trees in the area surrounding a nest. In this way, ants may affect lichen species composition due to temporal changes of the foraging trees according to aphid availability.

Regarding the growth form, control sites had a greater presence of crustose lichen species. Epiphytic lichens are often predated by invertebrates such as snails (Benesperi \& Tretiach 2004), and RWA presence may negatively affect invertebrate assemblages. Frizzi et al. (2018) have previously found in the same forest of this study that F. paralugubris negatively impacts invertebrates' presence, describing a clear decrease in their abundance in colonised areas. This could suggest that the decreased abundance of invertebrates feeding on lichens may positively influence the presence of foliose and fruticose lichens that may be more likely predated (Gauslaa et al. 2006).

It is also worth reporting that the geographic position seemed to have an effect in influencing lichen communities. Several studies have shown that epiphytic lichen species richness and composition are mainly influenced by microscale factors such as bark $\mathrm{pH}$, roughness, water holding capacity, and tree species, and macroscale factors such as temperature (Marini et al. 2011). Moreover, the difference in lichen species could be affected by the wide variety of growth forms, reproductive strategies, and photobionts that could allow the replacement of lost species. In our work, we tried to avoid the effect of these factors by comparing sites with similar pedoclimatic conditions. Additionally, the influence of the phorophyte was not an issue here, as only one tree species was present in both sites. However, it is evident that some microscale factors (i.e., at the plot scale) could not be controlled for, despite our efforts.

Our study also revealed a significant difference in $\beta$-diversity between sites with 
and without RWA. $\beta$-diversity was higher where RWA were present, and all its components (i.e., replacement, similarity and richness) were affected. The specific mechanism behind this pattern are not known and surely deserve further research, but in principle, the same mechanisms discussed to explain the observed differences in lichen functional diversity may apply here.

\section{Conclusion}

Our study revealed a significant effect of the presence of $F$. paralugubris on lichen communities and extended our knowledge on the impact of this introduced species on autochthonous communities. Our results suggest both a direct effect, with a physical dispersal of lichen propagules by ant workers, and an indirect effect, by ant predatory pressure on lichen herbivores. Our study is the first attempt to unveil the possible effects of RWA on lichen epiphytic diversity using a functional approach. We stressed that possible effects of the presence of RWA could be concentrated on species with specific functional traits. Nevertheless, further studies are needed to clarify the mechanisms involved in the interactions between RWA and lichen communities.

\section{Author contributions}

$\mathrm{RB}$ and $\mathrm{GS}$ conceived and designed the experiments. LDN, EB, RB,AM,FF, GS, MBC, $F M, Y S, C V$ and $P B$ collected the data. FF, LDN and AM performed data analysis. LDN and $A M$ wrote the first draft and contribute equally. All authors contributed extensively to the ideas, writing and discussions. Comments from two anonymous reviewers greatly improved the manuscript. The work was funded by grants of the University of Florence to GS and RB.

\section{Acknowledgements}

We are grateful to the Reparto Carabinieri per la Biodiversità di Pratovecchio e Pistoia for their assistance during field work.

\section{References}

Aho T, Kuitunen M, Suhonen J, Jäntti A, Hakkari $T$ (1999). Reproductive success of eurasian treecreepers, Certhia familiaris, lower in territories with wood ants. Ecology 80: 998-1007. doi: $10.1890 / 0012-9658$

Anderson MJ (2001). A new method for non-parametric multivariate analysis of variance. Austral Ecology 26: 32-46. - doi: 10.1111/j.1442-9993. 2001.01070.pp.x

André HM (1985). Associations between corticolous microarthropod communities and epiphytic cover on bark. Ecography 8: 113-119. - doi: 10.1111/j.1600-0587.1985.tb01161.x

Asplund J, Wardle DA (2017). How lichens impact on terrestrial community and ecosystem properties. Biological Reviews 92: 1720-1738. - doi: 10.1111/brv.12305

Bailey RH (1970). Animals and the dispersal of soredia from Lecanora conizaeoides NYL. Ex cromb. The Lichenologist 4: 256-256. - doi: $10.1017 /$ So024282970000294
Balzani P, Vizzini S, Frizzi F, Masoni A, Lessard JP, Bernasconi C, Francoeur A, Ibarra-Isassi J, Brassard F, Cherix D, Santini G (2021). Plasticity in the trophic niche of an invasive ant explains establishment success and long-term coexistence. Oikos 130 (5): 691-696. - doi: 10.1111/oik. 08217

Bartolini G, Grifoni D, Magno R, Torrigiani T, Gozzini B (2018). Changes in temporal distribution of precipitation in a Mediterranean area (Tuscany, Italy) 1955-2013. International Journal of Climatology 38: 1366-1374. - doi: 10.1002/joc. 5251

Benesperi R, Tretiach M (2004). Differential land snail damage to selected species of the lichen genus Peltigera. Biochemical Systematics and Ecology 32: 127-138. - doi: 10.1016/S0305-1978 (03)00141-8

Buhl J, Hicks K, Miller ER, Persey S, Alinvi O, Sumpter DJT (2009). Shape and efficiency of wood ant foraging networks. Behavioral Ecology and Sociobiology 63: 451-46o. - doi: 10.10 07/s00265-008-0680-7

Caradonna PJ, Burkle LA, Schwarz B, Resasco J, Knight TM, Benadi G, Blüthgen N, Dormann CF, Fang Q, Fründ J, Gauzens B, Kaiser-Bunbury CN, Winfree R, Vázquez DP (2021). Seeing through the static: the temporal dimension of plant-animal mutualistic interactions. Ecology Letters 24 (1): 149-161. - doi: 10.1111/ele.13623

Chapuisat M, Keller L (1999). Extended family structure in the ant Formica paralugubris: the role of the breeding system. Behavioral Ecology and Sociobiology 46: 405-412. - doi: 10.1007/ s002650050636

Clarke KR, Warwick RM (2001). Change in marine communities: an approach to statistical analysis and interpretation. Primer-E Ltd, Plymouth, UK, pp. 262.

Domisch T, Risch AC, Robinson EJH (2016). Wood ant foraging and mutualism with aphids. In: "Wood Ant Ecology and Conservation". Cambridge University Press, Cambridge, UK, pp. 145-176. - doi: 10.1017/CBO9781107261402.0 08

Ellis S, Robinson EJH (2016). Internest food sharing within wood ant colonies: resource redistribution behavior in a complex system. Behavioral Ecology 27: 660-668. - doi: 10.1093/beh eco/arv205

Frizzi F, Masoni A, Quilghini G, Ciampelli P, Santini $G$ (2018). Chronicle of an impact foretold: the fate and effect of the introduced Formica paralugubris ant. Biological Invasions 20: 35753589. - doi: 10.1007/s10530-018-1797-x

Frizzi F, Masoni A, Migliorini M, Fanciulli PP, Cianferoni F, Balzani P, Giannotti S, Davini G, Frasconi Wendt C, Santini G (2020). A comparative study of the fauna associated with nest mounds of native and introduced populations of the red wood ant Formica paralugubris. The European Journal of Soil Biology 101: 103241. doi: 10.1016/j.ejsobi.2020.103241

Frouz J, Jílková V, Sorvari J (2016). Contribution of wood ants to nutrient cycling and ecosystem function. In: "Wood Ant Ecology and Conservation". Cambridge University Press, Cambridge, UK, pp. 207-220. [online] URL: http://books. google.com/books?id=GpgODAAAQBAJ

Gauslaa Y, Holien H, Ohlson M, Solhy T (2006). Does snail grazing affect growth of the old for- est lichen Lobaria pulmonaria? The Lichenologist 38: 587-593. - doi: 10.1017/So024282906006 025

Giordani P, Rizzi G, Caselli A, Modenesi P (2016). Fire affects the functional diversity of epilithic lichen communities. Fungal Ecology 20: 49-55. doi: 10.1016/j.funeco.2015.11.003

Gonnelli V, Bottacci A (2009). Il clima di Sasso Fratino [The climate of Sasso Fratino]. In: La Riserva naturale integrale di Sasso Fratino: 1959-2009. 50 anni di conservazione della biodiversità [The integral natural reserve of Sasso Fratino: $1959-2009.50$ years of biodiversity conservation]. CFS/UTB, Pratovecchio, Arezzo, pp. 39-46. [in Italian]

Gorb E, Gorb S (2003). Seed dispersal by ants in a deciduous forest ecosystem: mechanisms, strategies, adaptations. Kluwer Academic Publishers, Dordrecht, The Netherlands, pp. 225. [online] URL: http://books.google.com/books? id=D82BqJQKXToC

Groppali R, Crudele G (2005). Le formiche del gruppo Formica rufa trapiantate nel Parco nazionale delle Foreste Casentinesi, Monte Falterona e Campigna [Red wood ants (Formica rufa group) introduced in the Foreste Casentinesi, Monte Falterona and Campigna National Park]. Quaderni di Studi e Notizie di Storia Naturale della Romagna, Cesena 20: 63-73. [in Italian]

Heinken T, Rohner M-S, Hoppert M (2007). Red wood ants (Formica rufa group) disperse bryophyte and lichen fragments on a local scale. Nova Hedwigia: Beiheft 131: 147-163. [online] URL: http://publishup.uni-potsdam.de/frontdoo r/index/index/docld/30639

Herrera CM, Pellmyr O (2009). Plant animal interactions: an evolutionary approach. Blackwell Science Ltd., Oxford, UK, pp. 334. [online] URL: http://books.google.com/books?id=u4jAB7_7sr sC

Hurtado P, Prieto M, Martínez-Vilalta J, Giordani P, Aragón G, López-Angulo J, Košuthová A, Merinero S, Díaz-Peña EM, Rosas T, Benesperi R, Bianchi E, Grube M, Mayrhofer H, Nascimbene J, Wedin M, Westberg M, Martínez I (2020). Disentangling functional trait variation and covariation in epiphytic lichens along a continentwide latitudinal gradient. Proceedings of the Royal Society B: Biological Sciences 287: 20192862. - doi: 10.1098/rspb.2019.2862

Kerney M (1999). Atlas of the land and freshwater mollusca of Britain and Ireland. Brill, Leida, The Netherlands, pp. 272.

Lach L, Parr C, Abbott K (2010). Ant ecology. Oxford University Press, Oxford, UK, pp. 432. [online] URL: http://books.google.com/books?id=vl wVDAAAQBAJ

Lavorel S, Grigulis K, McIntyre S, Williams NSG, Garden D, Dorrough J, Berman S, Quétier F, Thébault A, Bonis A (2008). Assessing functional diversity in the field - methodology matters! Functional Ecology 22: 134-147. - doi: 10.1111/j.13 65-2435.2007.01339.x

Lorentsson S, Mattsson J-E (1999). New Reports of soredia dispersed by ants, Formica cunicularia. The Lichenologist 31: 204-207. - doi: $10.1017 /$ So024282999000262

Marini L, Nascimbene J, Nimis PL (2011). Largescale patterns of epiphytic lichen species richness: photobiont-dependent response to cli- 
mate and forest structure. Science of the Total Environment 409: 4381-4386. - doi: 10.1016/j.sci totenv.2011.07.010

Masoni A, Frizzi F, Natali C, Bernasconi C, Ciofi C, Santini G (2019). Molecular identification of im ported red wood ant populations in the Cam pigna Biogenetic Nature Reserve (Foreste $\mathrm{Ca}$ sentinesi National Park, Italy). Conservation Genetics Resources 11: 231-236. - doi: 10.1007/s1268 6-018-0982-7

Matteucci E, Benesperi R, Giordani P, Piervittori $R$, Isocrono $D$ (2012). Epiphytic lichen communities in chestnut stands in Central-North Italy. Biologia (Bratislava) 67: 61-70. - doi: 10.2478/s1175 6-011-0145-8

Nascimbene J, Lazzaro L, Benesperi R (2015). Patterns of $\beta$-diversity and similarity reveal biotic homogenization of epiphytic lichen communities associated with the spread of black locust forests. Fungal Ecology 14: 1-7. - doi: 10.101 6/j.funeco.2014.10.006

Nash TH (2008). Lichen biology. Cambridge University Press, Cambridge, UK, pp. 502.

Nimis PL, Martellos S (2020). ITALIC 6.0 - the information system on Italian lichens. Web site. [online] URL: http://dryades.units.it/italic

Ohashi M, Kilpeläinen J, Finér L, Risch AC, Domisch T, Neuvonen S, Niemelä P (2007). The effect of red wood ant (Formica rufa group) mounds on root biomass, density, and nutrient concentrations in boreal managed forests. Journal of Forest Research 12 (2): 113-119. - doi: 10.1007/s10310-006-0258-z
Pike LH (1978). The importance of epiphytic lichens in mineral cycling. The Bryologist 81: 247-257. - doi: $10.2307 / 3242186$

Pla L, Casanoves F, Di Rienzo J (2012). Functional diversity indices. In: "Quantifying Functional Biodiversity". Springer, Dordrecht, Netherlands, pp. 27-51. - doi: 10.1007/978-94-007-26482_3

Podani J, Schmera D (2011). A new conceptual and methodological framework for exploring and explaining pattern in presence-absence data. Oikos 120: 1625-1638. - doi: 10.1111/j.16000706.2011.19451.x

Porada P, Van Stan JT, Kleidon A (2018). Significant contribution of non-vascular vegetation to global rainfall interception. Nature Geoscience 11: 563-567. - doi: 10.1038/s41561-018-0176-7

Punttila P, Niemelä P, Karhu K (2004). The impact of wood ants (Hymenoptera: Formicidae) on the structure of invertebrate community on mountain birch (Betula pubescens ssp. czerepanovii). Annales Zoologici Fennici 41: 429-446. [online] URL: http://www.jstor.org/stable/2373 5950

Rico-Gray V, Oliveira PS (2007). The ecology and evolution of ant-plant interactions. University of Chicago Press, Chicago, IL, USA, pp. 320. doi: 10.7208/chicago/9780226713540.001.0001 Risch AC, Ellis S (2016). Where and why? Wood ant population ecology. In: "Wood Ant Ecology and Conservation". Cambridge University Press, Cambridge, UK, pp. 81-105. [online] URL: http://books.google.com/books?id=otigDAAAQ
BAJ

Robinson EJH, Stockan JA, lason GR (2016). Wood ants and their interaction with other organisms. In: "Wood Ant Ecology and Conservation”. Cambridge University Press, Cambridge, UK, pp. 177-206. - doi: 10.1017/CBO97811072614 02.009

Stockan JA, Robinson EJH (2016). Wood ant ecology and conservation. Cambridge University Press, Cambridge, UK, pp. 304. [online] URL: http://books.google.com/books?id=GpgO DAAAQBAJ

Thunes KH, Gjerde I, Skartveit J (2018). The red wood ant Formica aquilonia (Hymenoptera: Formicidae) may affect both local species richness and composition at multiple trophic levels in a boreal forest ecosystem. Annales Zoologici Fennici 55: 159-172. - doi: 10.5735/086.055.0603 Wardle DA, Hyodo F, Bardgett RD, Yeates GW, Nilsson MC (2011). Long-term aboveground and belowground consequences of red wood ant exclusion in boreal forest. Ecology 92: 645-656. - doi: 10.1890/10-1223.1

Zuur A, leno EN, Walker N, Saveliev AA, Smith GM (2009). Mixed effects models and extensions in ecology with R. Springer, New York, USA, pp. 596. - doi: 10.1007/978-0-387-87458-6

\section{Supplementary Material}

Tab. S1 - Functional traits of lichen species.

Link: DiNuzzo_3897@supploo1.pdf 